\title{
REVIEW
}

\section{Probabilistic maturation reaction norms: their history, strengths, and limitations}

\author{
Ulf Dieckmannn $^{1, *}$, Mikko Heino ${ }^{2,1,3}$ \\ ${ }^{1}$ Evolution and Ecology Program, International Institute for Applied Systems Analysis, Schlossplatz 1, 2361 Laxenburg, Austria \\ ${ }^{2}$ Institute of Marine Research, PO Box 1870 Nordnes, 5817 Bergen, Norway \\ ${ }^{3}$ Department of Biology, University of Bergen, PO Box 7800, 5020 Bergen, Norway
}

\begin{abstract}
Probabilistic maturation reaction norms (PMRNs) are emerging as a flexible and general tool for characterizing phenotypic plasticity in maturation schedules. Describing an organism's probability of maturing as a function of its age and size, PMRNs offer several beneficial features: (1) PMRNs overcome systematic biases that previously marred the estimation of deterministic maturation reaction norms for populations with probabilistic growth and maturation; (2) PMRNs remove the effects of varying mortality rates and average juvenile somatic growth rates from descriptions of maturation schedules; (3) PMRNs are defined at the level of individuals and can thus be treated as phenotypes when applying methods of quantitative genetics; (4) PMRNs serve as indispensable ingredients in process-based dynamical models of a population's age and size structure; and (5) PMRNs are readily extended to include effects on maturation of individual or environmental factors other than age and size. Owing to this combination of features, PMRNs allow many effects of phenotypic plasticity to be stripped away from the description of maturation schedules, so that residual trends are suggestive of genetic adaptation in maturation schedules. Here we review the historical developments that led to the introduction of PMRNs and address frequently asked questions about their interpretation, utility, and application.
\end{abstract}

KEY WORDS: Maturation · Reaction norm · Phenotypic plasticity · Genetic adaptation · Fisheriesinduced evolution · Life-history transition · Energy allocation · Micro- and macroenvironment

- Resale or republication not permitted without written consent of the publisher

\section{INTRODUCTION}

Maturation is the most important life-history transition in plants and animals. Whereas some characteristics of organisms (including their length, weight, and condition) change gradually during their lifetime, and others (including age, as well as length in many species) even change monotonically, maturation involves a transition between 2 qualitatively different states, turning juveniles into adults. Understanding the proximate and ultimate determinants of maturation is one of organismal biology's central challenges. As must be expected, there are ecological and evolutionary determinants of maturation. The ecological determinants operate through phenotypic plasticity: the realized maturation schedules of individual organisms thus depend on the environmental conditions they are, or have been, experiencing. In contrast, the evolutionary determinants operate through genetic adaptation: the maturation schedules of populations of organisms thus depend on the selection regimes they have experienced.

Integrating the ecological and evolutionary dimensions of maturation into a synthetic framework for research has not been easy. Studies of phenotypically plastic maturation have not usually addressed evolutionary questions. Conversely, studies of genetic adaptation in the maturational process have not often 
accounted for phenotypic plasticity. Partly, this simply reflects the general difficulty in evolutionary ecology of bridging the gap between the timescales required for studying ecological and evolutionary change. Because of the disparate durations involved, ecological change is mostly directly observable in empirical analyses, whereas understanding evolutionary change often requires more complex, indirect, and/or theorybased analyses. Experimental protocols, statistical methods, comparative approaches, and theoretical models jointly accounting for phenotypic plasticity and genetic adaptation in maturation schedules thus remained beyond the research community's reach for a long time.

Here we discuss an approach, based on so-called probabilistic maturation reaction norms (PMRNs), that we believe offers the potential for overcoming these difficulties. The roots of this approach extend more than 2 decades into the past. First, we summarize background information on plastic and genetic maturation adaptation (see below); the subsequent section offers a historical overview, revisiting the salient scientific developments and reflecting on their significance in a broader context. The reaction-norm approach to maturation is also currently stimulating interesting discussions. In the third section below, we address the main questions and potential misunderstandings we have encountered in our dialogues with colleagues.

\section{PLASTIC AND GENETIC MATURATION ADAPTATIONS}

Variability in maturation is ubiquitous among species and individuals. This is just as expected, since maturation schedules are based on energy allocation strategies; such strategies are flexible, even within a given morphological bauplan or physiological setup. Moreover, differential energy allocations have substantial fitness implications, and optimal energy allocations change with environmental conditions. In fact, the flexibility of maturation schedules is so pronounced that researchers have taken to borrowing terminology from behavioral studies, and figuratively speak of a 'maturation decision' or 'decision to mature': After prioritizing energy allocation to somatic growth as a juvenile, when should an organism become adult and start investing in reproduction?

The balance between the fitness benefits of early maturation (increased survival to first reproduction and decreased generation time) and late maturation (increased body size and enhanced effective fecundity) involves several classical life-history tradeoffs. These include the tradeoffs between (1) current reproduction and survival, (2) current reproduction and growth, and
(3) current reproduction and condition (Stearns 1992). Maturation schedules adapt to environmental conditions under the constraints imposed by these tradeoffs, and therefore are far from arbitrary.

To understand maturation responses to environmental conditions, it is helpful to distinguish between 3 aspects of the environment: (1) The ancestral environment, characterized by environmental conditions that remain stable over generations and to which a population has had time to adapt through natural selection; (2) the macroenvironment (Gavrilets \& Scheiner 1993, Gavrilets \& Hastings 1994, Hartl \& Clark 1997), characterized by environmental conditions with predictable phenotypic effects collectively experienced by groups of individuals; (3) the microenvironment, characterized by environmental conditions that are specific to individuals. Along this gradient of environmental predictability, maturation responses are determined by different means: responses to the ancestral environment come about through genetic adaptation, responses to the macroenvironment are based on phenotypic plasticity, while responses to the microenvironment are typically regarded as developmental noise.

After genetic adaptation to the ancestral environment has run its course, the maturation schedule of a population in a habitat imposing, for example, low juvenile mortality will differ markedly from that of a population typically experiencing high juvenile mortality. As a result of phenotypic plasticity in response to the macroenvironment, maturation decisions will be affected by the environmental conditions individuals encounter. In terms of mechanism, the latter occurs for 3 related, yet separate, reasons. (1) Current environmental conditions constrain current energy allocations; for example, when energy intake is low, necessary allocations to maintenance will leave little room for allocations to growth or reproduction. (2) In the presence of positive temporal autocorrelations, the recent past offers valuable clues for anticipating environmental conditions in the immediate future; for instance, one month with good food supply is likely to be followed by another such month. (3) Past environmental conditions are bound to leave their mark on an individual, in terms of states such as length, weight, and/or condition, subsequently implying different optimal allocation strategies. For illustration, consider the benefits of allocating energy to survival, growth, condition, and current reproduction, which will trade off differently for a well fed specimen compared to an individual with poor body condition.

The considerations above make it evident that genetic and plastic adaptations in maturation schedules are inexorably intertwined. Whenever the relative roles of these 2 types of adaptation are not already known, the comprehensive understanding of maturation schedules will require an integrative approach. 


\section{HISTORICAL OVERVIEW}

Flexible responses and temporal trends in the maturation schedules of fishes have been described in many empirical studies. The references mentioned below are but a small sample.

\section{Maturation trends}

Alm (1959) was perhaps the first fisheries scientist to systematically examine plasticity in maturation in a major species of fish. Specifically, Alm investigated how size at maturation in Eurasian perch Perca fluviatilis varied with the somatic growth rates that individuals experienced during their juvenile period. Based on his experimental analyses, Alm suggested that size at maturation in this species was small for fast-growing individuals, larger for individuals experiencing intermediate juvenile growth rates, and smaller again for slow-growing individuals. The last relationship is particularly relevant for species exhibiting stunting: with a low expectation of future growth, maturing at an otherwise suboptimal small body size happens to be the best option available.

Early studies indicating that fishing can induce reductions in the mean length or age at maturation of target species include the following: Rollefsen (1938, 1953), Hansen (1949), Powles (1958), Garrod (1967), Hylen \& Dragesund (1973), Oosthuizen \& Daan (1974), Borisov (1978), Ponomarenko et al. (1980), and Hylen \& Rorvik (1983) on Atlantic cod Gadus morhua; Pitt (1975) on American plaice Hippoglossoides platessoides; Schaffer \& Elson (1975) on Atlantic salmon Salmo salar; Handford et al. (1977) on lake whitefish Coregonus clupeaformis; Tikhonov (1977) on yellowfin sole Limanda espersa; Templeman et al. (1978) and Templeman \& Bishop (1979) on haddock Melanogrammus aeglefinus; and Ricker (1981) on Pacific salmon Oncorhynchus spp.

In a comprehensive analysis of Atlantic groundfish stocks in the southern Gulf of St. Lawrence and on the Scotian Shelf, Beacham (1983a,b,c,d,e,f) reported significant declines (30 to $50 \%$ ) in mean age and length at maturation during extensive commercial exploitation in the 1960s and 1970s. The species analyzed were Atlantic cod Gadus morhua, haddock Melanogrammus aeglefinus, American plaice or long rough dab Hippoglossoides platessoides, yellowtail flounder Limanda ferruginea, witch flounder or grey sole Glyptocephalus cynoglossus, and greater argentine Argentina silus.

Beacham (1987, p. 152) proposed that researchers

may have difficulty accepting that size and age at maturity of groundfish is a dynamic character that responds to changes in population size or fishery selection.
Following up on earlier suggestions by Borisov (1978), Beacham (1987, p. 150) also explicitly highlighted the potential for fisheries-induced evolution in maturation schedules:

To the extent that size and age at maturity are genetically determined, fish which mature at smaller sizes or younger ages have a selective advantage during intensive fisheries. Genotypes that reproduce before being fully recruited to the fishery can have a selective advantage over those that mature at larger sizes or older ages.

He judiciously concluded that

one unresolved issue is whether the changes in size or age at maturity are a result of a density-dependent response to decreased stock size or a result of genetic change within a population.

Based on theoretical predictions of mortality-induced maturation evolution (Law 1979), and encouraged by matching experimental results in the water flea Daphnia magna (Edley \& Law 1988), Law \& Grey (1989) suggested that the determination of maximal sustainable fisheries yields should account for fisheries-induced evolution. Thirty years earlier, a review by Miller (1957) had still concluded that there was little evidence for any genetic adaptation caused by fishing. Popular articles by Sutherland (1990) and Law (1991) informed a wider audience about the perils of fisheries-induced evolution in general, and of fisheries-induced maturation evolution in particular. Similar caveats had already been raised by Nelson \& Soulé (1987) and were further explored at the scale of an edited volume by Stokes et al. (1993) and in the form of reviews by Smith (1994) and Sheridan (1995). These accounts made it unmistakable that understanding fisheries-induced maturation trends was no longer a challenge of fundamental biological interest alone, but was also begging ponderous questions of considerable socio-economic consequence for fisheries science and management. This conclusion has lost no force until today.

Reporting on the longest yet documented trends in fish maturation, Jørgensen (1990) (see also Godø 2000) showed that in Northeast Arctic cod Gadus morhua both age at maturation and size at maturation had been declining consistently since the 1920s. A similar long-term decline, between the periods 1904-1911 and 1960-1990, was demonstrated for North Sea plaice Pleuronectes platessa by Rijnsdorp (1989, 1993a,b). Publication of these seminal investigations let it appear increasingly unlikely that observed maturation trends could be interpreted as mere phenotypically plastic responses to decadal environmental fluctuations.

An overview by Trippel (1995) helped to draw attention to the ubiquity of maturation trends in marine fish populations: all around the globe, exploited fish were maturing at smaller size and younger age. Trippel summarized the 2 alternative hypotheses for explaining fisheries-induced maturation trends that had 
shaped the earlier discussions. The first hypothesis was based on phenotypic plasticity: fishing reduces stock biomass and density, and thus allows the remaining fish to grow faster and mature earlier. Such effects of fishing have traditionally been referred to as compensatory responses. The second hypothesis was based on genetic adaptation: fishing favors genotypes maturing at younger ages and smaller sizes. Such an explanation prominently implicates fisheries-induced evolution. Trippel (1995, p. 767) drew the conclusion that

despite arguments and evidence that evolution might be occurring in exploited fish populations, fishery managers have not considered it seriously.

This was so even though, according to his evaluation, shifts in maturity are most likely to be a consequence of a mix of factors having both compensatory and genetic origins

(Trippel 1995, p. 766-767). Trippel also explained that studies of fisheries-induced maturation evolution would need to account for the fact that

genetic influence on age at maturity acts in the form of a capability with rather wide latitude (i.e. phenotypic plasticity) and not by strict age-specific inheritance of age at maturity from parent to progeny

(Trippel 1995, p. 766).

\section{Strategies for disentangling phenotypic plasticity and genetic adaptation}

With the recognition thus becoming inescapable that neither phenotypic plasticity nor genetic adaptation could be left out of empirical or theoretical analyses of fisheries-induced maturation trends, appropriate methods for first respecting and then disentangling phenotypic plasticity and genetic adaptation had to be found. Over the past 2 decades, 4 qualitatively different strategies - respectively based on experimental manipulation, comparative studies, countergradient or countertrend variation, and reaction norm analysis have been put forward. We outline these alternative approaches in turn below.

The first strategy operates through controlled experimental manipulation. The best example is provided by a remarkable line of research extending over the past 25 years, through which Reznick and colleagues investigated life-history variation in the Trinidadian guppy Poecilia reticulata (see Reznick \& Ghalambor 2005 for a brief overview). Combining an experimental approach in the field and laboratory with comparative studies, Reznick and colleagues demonstrated that maturation schedules in the small, fast-growing, and short-lived guppy systematically varied with predation-induced mortality (Reznick \& Endler 1982), that these differences were partly genetic (Reznick 1982, Reznick et al. 1996) and partly plastic (Reznick 1990), and that considerable maturation evolution could occur in the course of just 7 to 18 generations (Reznick et al. 1990, 1997). Phenotypic plasticity in maturation schedules of Trinidadian guppies was also found to go beyond the simple pattern that would result if size at maturation were fixed and age at maturation merely varied inversely with juvenile growth rate (Reznick 1990).

A second strategy is based on comparative studies. After documenting systematic differences in maturation between different local populations as a first step, hypotheses about the underlying causes are established in a second step by identifying factors that significantly covary with maturation across populations. As a third step, additional information must be used to evaluate the extent to which putative local adaptations to the identified factors are genetically based. This third step can involve the following: (1) common-garden rearing, as in a study by Goto (1993) on maturation plasticity in river sculpin Cottus hangiongensis; (2) successive exclusion of alternative explanations relying on phenotypic plasticity, as in a study by Johnson \& Belk (1999) on maturation evolution in Utah chub Gila atraria; or (3) testing how well the observed differences agree with theoretical predictions based on life-history evolution, as in a study by Hutchings (1993) on maturation evolution in brook trout Salvelinus fontinalis.

A third strategy seeks to identify cases in which phenotypic variation caused by phenotypic plasticity and genetic adaptation point in opposite directions. It is in this vein that Trippel (1995, p. 766) suggested that

evidence contrary to the compensatory theory may assist in building support for the effects of inheritance on age at maturity.

In other words, if opposite directions are predicted for phenotypic changes based on plastic and genetic effects, and 1 direction is observed, then it does not qualitatively matter that both effects may be acting jointly, since the dominating effect is likely to exist. For example, if age at maturation is observed to decrease while temperatures fall and stock densities rise, an explanation based on genetic adaptation will be strengthened, since the alternative explanation based on phenotypic plasticity predicts the reverse trend. Such phenotypic patterns in time can aptly be characterized as countertrend variation (CnTV), in analogy to phenotypic patterns in space described as countergradient variation (CnGV). According to Conover \& Schultz (1995), the latter are said to occur when genotypes are distributed across an environmental gradient in nature such that genetic influences more than counteract environmental influences on a trait. Evidence suggestive of fisheries-induced evolution and strengthened by the observation of countertrend vari- 
ation has been put forward, for example, by Polovina (1989; in the Hawaiian spiny lobster Panulirus marginatus: size at onset of egg production declined even though population density decreased) and by Olsen et al. (2005; in northern cod Gadus morhua: age at maturation declined even though growth rates decreased).

Circumstances under which one of the 3 approaches outlined so far can be applied are rather restrictive, since they require, respectively, experimental treatment (not an option for most marine species), spatial replication (problematic for marine stocks that intermingle or differ in too many environmental factors all at once), or countertrend variation (dependent on lucky coincidence and becoming increasingly unlikely as the number of considered environmental factors is increased). It is for these reasons that reliable conclusions about fisheries-induced maturation evolution remained stalled for decades.

\section{Maturation reaction norms}

Known as reaction-norm analysis, a fourth strategy for disentangling phenotypic plasticity and genetic adaptation in maturation schedules eventually helped to overcome this deadlock. Stearns (1983), Reznick (1990), and Rijnsdorp (1993a,b) put forward the same idea: reaction norms of fish maturation had to be considered to account for phenotypic plasticity, and these reaction norms had to be tested for temporal trends to evaluate whether or not genetic adaptations in the maturation schedules of fish were occurring. This approach naturally resulted from reaction norms having become appreciated, since the 1960s, as the most suitable descriptors of phenotypic plasticity (Sarkar 1999). The only open question was: How are maturation reaction norms to be defined?

A partial answer was provided in the work of Stearns and colleagues, who introduced maturation reaction norms to fish demography in order to describe how age and size at maturation were affected by growth rates (Stearns 1983, Stearns \& Crandall 1984, Stearns \& Koella 1986). This approach gave rise to bivariate reaction norms (Schlichting \& Pigliucci 1998, p. 58): 1 environmental variable, average juvenile somatic growth rate, affects 2 phenotypic variables, age at maturation and size at maturation. While these dependences could alternatively be expressed by 2 univariate reaction norms - one describing age at maturation as a function of growth rate, the other describing size at maturation as a function of growth rate-the elegance of Stearns' construction derives from using the 2 phenotypic variables, size and age at maturation, as the axes of a single 2-dimensional diagram, capturing the environmental factor, average somatic growth rate during the juvenile period, by their ratio. For any observed combination of size and age at maturation, the corresponding average juvenile somatic growth rate is given by the slope of the line connecting this combination to the diagram's origin. An additional benefit was that growth trajectories could readily be superimposed on these diagrams, so that the age and size at maturation resulting for a given juvenile growth trajectory and maturation reaction norm was easily predicted by the curves' intersection. Stearns (1983, p. 73) rightly argued that the reaction norms thus defined constitute 'the minimal definition of the [maturation] phenotype necessary to understand genetic change'.

A limitation of the maturation reaction norm concept as introduced by Stearns and colleagues was that it assumed maturation to occur deterministically along the maturation reaction norm. In other words, for a given maturation reaction norm and a given juvenile growth trajectory, maturation was predicted to occur exactly at their intersection, resulting in a precise combination of age and size, without variation. This implied that an individual's probability of maturing had to jump from 0 to 1 abruptly when its growth trajectory crossed the maturation reaction norm curve. The same notion of deterministic maturation reaction norm was discussed by Reznick $(1990,1993)$ in the context of guppy maturation, and continues to be important in contemporary theoretical studies (e.g. Berrigan \& Koella 1994, Day \& Rowe 2002, Ernande et al. 2004, Burd et al. 2006). There have also been many other life-history models in which either the phenotypic age at maturation (e.g. Heino 1998) or the phenotypic size at maturation (e.g. Gårdmark \& Dieckmann 2006) evolves; the latter 2 approaches are equivalent if there is no variation in growth. As was already pointed out by Stearns (1983), assuming the phenotypic age or size at maturation to be fixed is equivalent to assuming either vertical or horizontal deterministic maturation reaction norms. In natural populations, however, maturation ages and sizes tend to exhibit considerable phenotypic and genotypic variation even along given growth trajectories. The simple reason is that an individual's age and size do not usually suffice for predicting its maturation status with certainty. And even when other or additional macroenvironmental factors are considered, variation in microenvironmental factors will continue to imply maturation uncertainty.

\section{Defining PMRNs}

It is thus clear that maturation processes in most organisms will have to be described probabilistically. This conclusion was indeed foreshadowed in the context of metamorphosis research by Wilbur \& Collins 
(1973), who suggested describing an individual's probability of metamorphosing as a function of its weight and recent weight increase. Likewise, an individual's probability of maturing can be described as a function of its size and average juvenile somatic growth rate, or equivalently, as a function of its size and age. An early, still only semi-quantitative, response to this challenge was offered by Policansky (1983).

First attempts at defining probabilistic maturation reaction norms (PMRNs) took another route and were based on estimating the fraction of mature individuals in a population as a function of their age and size. This approach appears to have been considered independently, as suggested by the absence of any cross-citations, by Perrin \& Rubin (1990), Rijnsdorp (1993a), Haugen (2000), and Morita \& Morita (2002). Defining PMRNs in terms of the probability of being mature was certainly tempting, since it naturally extended the maturity-ogive concept, widely used in stock assessments, from 1 dimension (fraction mature as a function of either age or size) to 2 dimensions (fraction mature as a function of age and size). Statistical methods for estimating maturity ogives were thus already well established. Unfortunately, these attempts suffered from 2 main drawbacks. (1) Maturity ogives are properties of populations that have no counterpart at the level of individuals, and therefore cannot be interpreted as phenotypes for which evolution could induce genetic adaptations. (2) Even more importantly, maturity ogives are not only describing the maturation process itself, but also vary with the growth and mortality of individuals. Accordingly, maturity ogives change when conditions for growth and/or mortality are altered. This means, in particular, that maturity ogives cannot help to discriminate between genetic adaptations in maturation schedules and phenotypically plastic maturation changes resulting from variations in growth conditions.

The PMRNs introduced by Heino et al. (2002a) helped to overcome these problems. Instead of describing an individual's probability of being mature as a function of its age and size, PMRNs describe an individual's probability of becoming mature (typically, during 1 season) as a function of its age and size. PMRNs account for the inherent stochasticity of the maturation process by allowing an individual's probability of maturing to increase from 0 to 1 continuously, instead of jumping from 0 to 1 abruptly along a deterministic reaction norm. This approach offers a number of advantages. (1) The estimation of PMRNs overcomes systematic biases that result when deterministic maturation reaction norms are estimated for populations with probabilistic growth and probabilistic maturation. (2) PMRNs remove the effects of varying mortality rates and/or average juvenile somatic growth rates from descriptions of maturation schedules. (3) PMRNs are defined at the individual level. They can thus be treated as phenotypes when applying methods of quantitative genetics, so that population-level polymorphisms in maturation schedules can be analyzed correctly. (4) PMRNs serve as indispensable ingredients in process-based dynamical models of a population's age and size structure.

\section{Estimating PMRNs}

Several statistical techniques have been introduced to estimate PMRNs. When age- and size-specific densities of immature and newly matured individuals are known, PMRNs can be estimated as described by Heino et al. (2002a). In particular, in semelparous fish all mature individuals are newly matured, so that the estimation method of Heino et al. (2002a) can be applied directly. When densities of immature and mature individuals are known, but newly matured individuals (first-time spawners) cannot be distinguished from those that already matured earlier (repeat spawners), PMRNs can be estimated using auxiliary information on growth trajectories, as described by Barot et al. (2004a) and Heino et al. (2007). When newly matured individuals can be distinguished, but densities of only mature individuals are known, PMRNs can be estimated using auxiliary information on the average shape of growth trajectories and age-based maturity ogives, as described by Heino et al. (2002b). Finally, when individual ontogenetic trajectories can be observed in full, which requires repeated non-lethal observations and thus is impractical for field studies of marine fish, PMRNs can be estimated using methods analogous to survival analysis as described by Van Dooren et al. (2005).

\section{Applying PMRNs}

To date, PMRNs have been estimated for more than a dozen fish stocks. Relevant empirical studies include the following: Heino et al. (2002c), Barot et al. (2004b), and Olsen et al. $(2004,2005)$ on various populations of Atlantic cod Gadus morhua; Grift et al. (2003) on plaice Pleuronectes platessa; Engelhard \& Heino (2004a,b) on Atlantic herring Clupea harengus; Barot et al. (2005) on 3 populations of American plaice Hippoglossoides platessoides; Dunlop et al. (2005) on smallmouth bass Micropterus dolomieu; and Haugen \& Vøllestad (2007) on grayling Thymallus thymallus. In all of these studies growth-related phenotypic plasticity could be stripped from the description of maturation schedules, and in almost all of them long-term trends in maturation schedules were documented. That maturation trends remain ubiquitous, even when growth-related phenotypic plasticity is controlled for, rules out compensatory growth as 
a sufficient explanation of these trends and also makes it unlikely that idiosyncratic, region- or stock-specific mechanisms could fully explain these widespread trends. The hypothesis of fisheries-induced evolution thereby gains strength as the most parsimonious explanation of maturation trends observed worldwide.

Age and size alone are almost never sufficient for predicting maturation probabilities with certainty. Therefore, the forecasting of these probabilities can potentially be improved by accounting for additional factors. In particular, body condition has been shown to affect the maturation process (e.g. Bernardo 1993, Metcalfe 1998, Marteinsdottir \& Begg 2002). Moreover, even though size is often conveniently measured in terms of body length, it could alternatively be measured in terms of body weight. Three questions thus naturally emerge. Should length or weight be preferred as a measure of body size in PMRNs? What improvements in the predictive power of PMRNs may be gained by accounting for body condition? Can the trends observed in the PMRNs of many species be explained in terms of phenotypic plasticity based on body condition, so that these trends vanish once the effects of body condition on maturation probabilities are accounted for?

These questions have been addressed in a study by Grift et al. (2007) on maturation in North Sea plaice Pleuronectes platessa. It was shown that PMRNs based on age and weight provide slightly more accurate approximations of maturation probabilities than PMRNs based on age and length, but also that weightbased PMRNs imply much wider spreads of maturation probabilities than length-based PMRNs. Since weights exhibit much stronger fluctuations in the course of a season than lengths, weights will usually have to be normalized to a particular date during the season, a requirement that introduces additional assumptions and uncertainties into the estimation of maturation probabilities. Grift et al. (2007) thus suggested that, on balance, length-based PMRNs may be preferred.

The study by Grift et al. (2007) is also the first to report 3-dimensional PMRNs, alternatively based on age, length, and condition, or on age, weight, and condition. On this basis, Grift et al. (2007) demonstrated that - at least for North Sea plaice, which offers one of the best datasets internationally available for assessing changes in the maturation schedules of exploited marine fishes - incorporating body condition into the estimation of maturity probabilities increased the explained deviance only slightly, from $44-48 \%$ to $51-52 \%$. The resultant 3-dimensional PMRNs not only showed how, at given size and age, maturation probability increased with condition, but also exposed that this impact of condition diminished with age.

Finally, the results reported by Grift et al. (2007) revealed several interesting temporal trends. (1) Clear residual trends towards maturation at younger ages and smaller sizes remained even after removing plastic effects on maturation captured by age, length, weight, and condition. (2) The probabilistic spread of both length- and weight-based PMRNs was found to have shrunk significantly over time, which means that maturation in North Sea plaice has become more deterministic over the course of the last half century. (3) Age and condition, as opposed to size, are nowadays affecting the maturation probabilities of North Sea plaice less than they did decades ago.

Mollet et al. (2006) estimated 3-dimensional PMRNs for North Sea sole Solea solea, and extended the analysis to include the effects of ambient temperature. This extension is interesting, since temperature might have a direct impact on maturation, over and above its indirect impact on maturation through its effect on growth. Again, the question was whether the observed longterm trends in sole maturation towards younger ages and smaller sizes would vanish once phenotypic plasticity based on body condition or on the temperature experienced prior to maturation was accounted for. This turned out not to be the case. Mollet et al. (2006) thus concluded that their results provided additional support for fisheries-induced maturation evolution, as more explanatory variables were accounted for. In a similar vein, Baulier et al. (2006) took the analysis of condition effects further by evaluating body condition in terms of the hepatosomatic index, which is based on liver weight, rather than in terms of Fulton's condition index, which is based on total weight. Using this physiologically more accurate measure in estimating 3dimensional PMRNs based on age, length, and condition, Baulier et al. (2006) found that a long-term trend towards earlier maturation, consistent with fisheriesinduced maturation evolution, remained for all analyzed populations (NAFO divisions 2J3KL, 3Ps, and 3NO) of Atlantic cod Gadus morhua, even after the effects of hepatosomatic index were accounted for.

\section{PITFALLS OF UNDERSTANDING}

In the following section we address some frequently asked questions about PMRNs. In our experience, the issues touched on by these questions may sometimes result in pitfalls of understanding for scientists not yet familiar with this approach.

\section{Is the term 'reaction norm' appropriate?}

Norms of reaction describe how environmental factors influence phenotypic expression (Woltereck 1909, Schmalhausen 1949, Bradshaw 1965, Schlichting 
1986). Reaction norms will usually be shaped by the ancestral environment of a population, endowing individuals with a flexible response to the variable macroenvironmental conditions they encounter and thereby contributing to the maximization of their lifetime reproductive success (Schlichting \& Pigliucci 1998).

The preceding section has documented that maturation reaction norms were proposed-by Stearns (1983), Stearns \& Crandall (1984), Stearns \& Koella (1986), Reznick (1990), Perrin \& Rubin (1990), and Rijnsdorp (1993a) - for the explicit purpose of capturing the salient, but of course not all, aspects of phenotypic plasticity in maturation schedules. The discussion above hopefully has also shown why reaction norms should indeed be regarded as the most suitable conceptual tools for achieving this purpose. A growing acceptance of this conclusion in the context of fish maturation can be regarded as no more than a postscript to developments that permeated evolutionary ecology decades ago (Sarkar 1999).

We find that several uncertainties lead to concerns about using reaction norms for capturing maturation plasticity.

(1) Since reaction norms were not commonly used in fisheries science until recently, researchers in this field are bound to display healthy skepticism towards an initially unfamiliar concept. Naturally, this effect is expected to wear off with time.

(2) Maturation reaction norms are never expected to account for all phenotypic plasticity in maturation. In that regard, they are no different to reaction norms in other areas of evolutionary ecology. Norms of reaction quantify phenotypic responses to variation in one or more specific macroenvironmental factors, and always operate under the 'ceteris paribus' assumption that all other environmental factors are equal. Consequently, the deterministic part of PMRNs (characterized by the overall shape of isoprobability contours) captures the plastic maturation response to the considered macroenvironmental factor(s), while their probabilistic part (characterized by the spread of isoprobability contours) accounts for the noise imposed by the microenvironment in conjunction with macroenvironmental factors that are unaccounted for.

(3) It seems that some misunderstandings easily arise from the bivariate nature of deterministic maturation reactions norms. As explained above, such reaction norms describe how age and size at maturation (a bivariate phenotypic character) depend on average juvenile somatic growth rates (a univariate environmental factor). That the environmental factor is not displayed on 1 axis of the reaction-norm diagram, as would be expected for univariate reaction norms, is sometimes seen as confusing, even though bivariate reactions norms are part of the standard repertoire of plasticity research (Schlichting \& Pigliucci 1998, p. 58). For probabilistic maturation reaction norms, the correct interpretation is even more subtle: environmental variation is measured in terms of growth trajectories (a multivariate factor), while phenotypic variation is measured in terms of maturation probabilities along those growth trajectories (a multivariate character). The resultant dependence is then usually displayed by showing maturation probability as a function of size at age, thus averaging over all growth trajectories that may lead to any particular size at age.

(4) One might be tempted to stipulate that phenotypic plasticity should always be expressed in response to obvious indicators of environmental variation, such as ambient temperature or nutrient level. Despite the intuitive appeal of this, the notion of macroenvironment established in quantitative genetics (Gavrilets \& Scheiner 1993, Gavrilets \& Hastings 1994, Hartl \& Clark 1997) is considerably more encompassing: a macroenvironment can be defined in terms of the ontogenetic change it engenders. In general, there are many ways to characterize a macroenvironment. In the present context, a particularly relevant option is to characterize the macroenvironment in terms of the growth trajectory it engenders. All individuals exhibiting that growth trajectory will then have experienced the same macroenvironment, and vice versa. This notion is more grounded in biological reality than may be evident at first sight. In particular, the growth of fishes is affected by a great many environmental factors; these include the densities of all relevant types of prey, the densities of conspecific and heterospecific competitors, ambient temperature, and environmental factors affecting growth by requiring more or less energy investment into other functions. Moreover, these factors are bound to vary with time within and between seasons. Separately accounting for all of their effects therefore is an overwhelming task. Instead, it is much more practical to let the organisms themselves do the integration over time and environmental effects, resulting in environmental variation being characterized by readily observable changes of individual states, such as size at age.

(5) One may wonder whether reaction norms ought to be defined for genotypes or populations. In a review of one of the few textbooks devoted to phenotypic plasticity (Pigliucci 2001), Fuller (2003, p. 387) highlighted this common source of confusion:

Pigliucci initially defines 'plasticity' as the property of a genotype [...] However, many of the studies he cites as examples of plasticity [...] measure plasticity not on genotypes but families.

Of course, this is just as expected: when quantifying phenotypic plasticity in the wild, clonal lineages or inbred lines are not typically available. It is therefore 
unavoidable that almost all reaction norms measured in the field must be interpreted as population-level weighted averages of the underlying genotype-level reaction norms, with genotype frequencies serving as the weights. Sarkar \& Fuller (2003, p. 106) have suggested referring to genotype-level reaction norms as 'standard norms of reaction', while using the term 'generalized norms of reaction' for those norms of reaction that quantify 'plasticity at the level of populations or subspecies within a species, species within a genus, or taxa at higher levels.' While any such terminology has yet to become commonly established, highlighting the conceptual difference between genotype-level and population-level reaction norms is highly recommendable. In particular, plasticity researchers must be aware of this distinction when pursuing challenges like developing the quantitative genetics of reaction norms (Gomulkiewicz \& Kirkpatrick 1992, Gavrilets \& Scheiner 1993, Heino et al. 2007) or when comparing population-level reaction norms with genotype-level reaction norms, where the latter are available.

Weighing up these considerations, it seems as though there is good scientific reason for continuing to use the term 'maturation reaction norm' in line with traditions already established a quarter of a century ago. Ultimately, however, the question of how broadly or narrowly one would wish to define reaction norms is a matter of semantics. The term 'maturation schedule' may actually offer a useful alternative for referring to PMRNs whenever one seeks to avoid technical terminology or where connoting the traditions of plasticity research is not intended.

\section{What happens to PMRN analyses when growth rates are under genetic control?}

There is every reason to believe that the growth trajectories of many organisms, including those of fishes, are not only affected by environmental conditions but also possess a heritable component (e.g. Conover \& Munch 2002, Birkeland \& Dayton 2005; also many breeding programs in aquaculture are squarely based on the heritability of growth-related variation). So, since growth is not a purely environmental factor, may we still examine phenotypic plasticity in response to growth variation? Of course we may, as long as growth has an environmental component - and it always will have, owing to its critical dependence on energy intake. Some subtleties, however, have to be understood before the implications of this conclusion can be appreciated in full.

A first, and temptingly simple, approach to addressing the issue is to point out that, especially in the wild, environmental variation in growth usually exceeds genetic variation in growth by far. On this basis, one may then argue that growth is mainly environmentally determined, so that effects implied by any partial genetic determination of growth can be treated as small and inconsequential. This view closes the argument quickly and may even be essentially correct for marine fishes living in highly unpredictable environments.

At a second level of understanding, one will appreciate that as long as growth and PMRNs are genetically independent, genetic variation in growth will have much the same effect as environmental variation and only influence how a PMRN is sampled. If environmental variation in growth is small while there are, for example, 2 main growth genotypes in a population one implying slower growth and the other faster growth - a bimodal distribution of growth trajectories may result. This, however, has no bearing on the estimation or interpretation of PMRNs, since PMRNs describe the probability of becoming mature, conditional on having reached a certain age and size. Therefore, a potential bimodality in the distribution of growth trajectories, or any other effect of growth genetics on them, does not affect the conditional probability of maturing that is captured by PMRNs.

To reach a third level of understanding, we have to consider cases in which growth trajectories not only possess a large genetic variance but also exhibit a large genetic covariance with PMRNs (with both quantities being measured relative to the total phenotypic variance in growth). In these cases, an individual's growth trajectory not only determines its size at age but also affects, through genetic correlations, its genotype-level PMRN. Just as before, however, the population-level PMRN results from averaging genotypelevel PMRNs over the many alternative growth trajectories that lead to a given size at age. While this averaging becomes more complicated, the interpretation of the population-level PMRN remains unaffected.

Genetic dependence between growth and maturation will of course affect the evolution of maturation schedules: with such covariation, selection responses in maturation genetically imply growth evolution, just as well as selection responses in growth genetically imply maturation evolution. Such correlated selection responses at the level of quantitative traits are analogous to the phenomenon of 'genetic hitchhiking,' well known at the level of genes (Maynard Smith \& Haigh 1974). Nevertheless, such dependences have no bearing on the use of PMRNs for detecting evolutionary changes in maturation schedules.

The salient difference between cases with and without genetically imposed growth-maturation covariation is the causal interpretation of genetic adaptations in PMRNs. When such covariation is strong, one cannot read- 
ily determine whether evolving maturation schedules are under direct selection, or indirectly respond to selection on growth. In reality, selection will likely affect both traits simultaneously, so that the observed evolutionary response is a compromise constrained by whatever genetic growth-maturation covariation exists.

We can thus conclude that the estimation and interpretation of population-level PMRNs are immune to the existence of heritable variation in growth, and even to the existence of heritable covariation between growth and maturation. Also, the interpretation of changes in population-level PMRNs is unaffected by heritable growth variation, and is affected by heritable growth-maturation covariation only if this covariation is strong. The interplay between phenotypic plasticity and genetic adaptation in both growth and maturation is an exciting topic of life-history research, but does not affect how PMRNs can and should be used.

\section{Are maturation ogives and PMRNs interchangeable?}

PMRNs superficially resemble maturity ogives: both have something to do with maturity and can be expressed as probabilities that depend on age and size. However, while PMRNs describe the probability of becoming mature, maturity ogives describe the probability of being mature. At first sight, this subtle difference may appear inconsequential and may even lead to the idea that PMRNs and maturity ogives could be used interchangeably. This is wrong. Rather, PMRNs and maturity ogives are fundamentally different; both have important uses, but one cannot be used in lieu of the other.

Maturity (described by maturity ogives) is to maturation (described by PMRNs) what size is to growth: growth and maturation are processes that lead to changes in individual states, in this case in size and maturity, respectively. Assessing an individual's growth process by measuring its size is as good or bad as trying to assess the maturation process by measuring maturity; it is bad, since both size and maturity are poor measures of the underlying processes if used directly, but good, since through proper transformations they can reveal critical information about the underlying processes. For growth, this is very obvious: one cannot replace growth rate with size, but if an individual's size at 2 ages is known, simple subtraction and division by the corresponding time interval yields an estimate of the average growth rate during that time interval. For maturation, an analogous calculation scheme for transforming from ogives to PMRNs exists; however, this turns out to be a bit more complicated, and in general requires additional information on growth and mortality (Barot et al. 2004a).
Maturity ogives are useful for describing how maturity in a population depends on the age and/or size of individuals. However, for describing the process of maturation, maturity ogives are not directly helpful because maturation is but one of the 3 processes determining the dependence of maturity on age and size, the other 2 processes being growth and mortality. By contrast, a PMRN describes the maturation process alone. The main confounding effects of growth and mortality are removed because a PMRN describes the probability of maturing conditional on reaching a certain age and size, with growth and mortality determining the probability of reaching - i.e. growing to and surviving until - that age and size. PMRNs can thus be viewed as fundamental life-history characteristics describing the maturation process. In contrast, maturity ogives are compound demographic characteristics describing the joint outcome of the 3 processes of maturation, growth, and mortality.

\section{Is it a problem that PMRNs may contain midpoints that lie outside the observed size range?}

Full description of a PMRN involves describing the probability of maturing for all relevant combinations of age and size. This gives rise to reaction norm surfaces in diagrams that use age, size, and maturation probability as axes. Parts of these surfaces are then sampled by the relevant growth trajectories. Since such surface plots are difficult to read quantitatively, it has become customary to illustrate the shape of a PMRN surface through percentile curves in contour plots that use age and size as axes. The simplest illustration is to show only the midpoints, i.e. the sizes for each age at which the probability of maturing equals $50 \%$. For some ages, this midpoint may easily lie outside the range of sizes observed at that age. This is typical, particularly for the youngest and oldest ages for which a PRMN is estimated. At these ages, the population's average probabilities of maturing are close to 0 or 1 , respectively, so that unrealistically large or small sizes would be required for individuals to experience a maturation probability of $50 \%$. Is this a problem? Conceptually not, since it merely signals that percentile curves for other maturation probabilities, closer to the population's average for the considered age, should be used to show the PMRN's shape at that age. Simply drawing a midpoint curve at $50 \%$ maturation probability does not imply that its entirety would be sampled by actual growth trajectories.

Two conclusions can be drawn from this brief discussion. (1) PMRN midpoints that are extrapolated from the observed size range are bound to be more prone to estimation errors than PMRN midpoints that are inter- 
polated. As in regression analyses, estimations are least uncertain where data are most abundant. Midpoints for early and late maturation thus typically exhibit larger confidence intervals than those for intermediate ages. (2) The shape of PMRNs should best be documented by showing multiple isoprobability contours. The extent to which individual contours are shown across ages can then be limited to the range spanned by observed growth trajectories. This will often result in drawing percentile curves for 10 or $25 \%$ maturation probabilities at young ages, for a wider range of maturation probabilities including $50 \%$ at intermediate ages, and for 75 and $90 \%$ maturation probabilities at old ages. Indeed, showing a PMRN's isoprobability contours for the size ranges observed across ages will give the best possible impression of the actual maturation dynamics of a specific population. If these contours are narrowly spaced, maturation is close to deterministic. Widely spread isoprobability contours, on the other hand, signal that the maturation schedule is only weakly influenced by age and size. This may occur when there is significant micro- or macroenvironmental variation that is unaccounted for.

\section{Does the PMRN approach assume that age and length are the only determinants of maturation?}

By definition, PMRNs for age and size use age and size for describing systematic variations in maturation probability. Of course this does not imply perfect determination of maturation by age and size alone. In fact, the very reason that a probabilistic approach is called for is that age and size almost always are incomplete determinants of maturation. Not only are age and size far removed from the proximate triggers of maturation (Bernardo 1993), but also better predictions of maturation probability can often be obtained by taking into account an individual's energetic state, as well as its energy acquisition prospects (Metcalfe 1998, Thorpe et al. 1998, Morita \& Fukuwaka 2006). In temporally autocorrelated environments, the latter can even be predicted from recent somatic growth rates. Also, directly accounting for environmental variables may improve predictions. For example, temperature affects many physiological processes, including growth, and may also have direct effects on maturation, at the very least by providing seasonal cues (Thorpe et al. 1998, Huber \& Bengtson 1999).

Experience has shown that age and size together do provide useful information for describing which individuals are more likely to mature. Size alone is relevant, since physiological and ecological constraints probably impose some limits on how large an individual has to become before it can successfully mature and reproduce (Roff 1991, Metcalfe 1998). It is less clear whether age has any significance of its own. In organisms experiencing either senesce or repeated (even periodic) habitat destruction, a direct age effect must be expected, since mortality rates are then agedependent. In general, however, it is the combination of age and size that gives information about the average somatic growth rate an individual has experienced in its past, which serves as an important indication of how well that individual has been faring.

Most PMRNs estimated to date have used age and length as the only explanatory variables. However, the concept of PMRN is more general, and nothing prevents the inclusion of other explanatory variables, either in addition to or in place of age and length. The role of other explanatory variables in the maturation of female North Sea plaice Pleuronectes platessa has been explored by Grift et al. (2007), who considered weight and condition (measured by Fulton's condition index) in addition to age and length. As expected, accounting for variation in body condition explains more of the variation in maturation probability than is possible based on age and length alone. However, the gain is small, and the extra demands on the dataset and its analysis are not negligible. Related studies by Baulier et al. (2006) and Mollet et al. (2006) on Northeast Arctic cod Gadus morhua and North Sea sole Solea solea, respectively, have already been summarized in the preceding section. Also, Morita \& Fukuwaka (2006) have shown how using information on past growth increments in chum salmon Oncorhynchus keta can strengthen the prediction of maturation probabilities relative to using only total length at age.

In practice, the choice of explanatory variables is primarily a question of data availability: it is this availability rather than the PMRN method itself that imposes limitations. Wherever feasible, the inclusion of additional explanatory variables in the estimation of PMRNs is to be encouraged. Once enough PMRN studies have been carried out for different sets of explanatory variables, conclusions may perhaps be drawn about an optimal general set. At the present stage of our knowledge, however, using age and length together appears to offer the best practical compromise between predictive power and wide applicability.

\section{Does the PMRN approach claim to disentangle all phenotypic plasticity from genetic changes?}

Maturation reaction norms in general, and PMRNs in particular, help to disentangle the effects of phenotypic plasticity and genetic adaptation on maturation (Stearns 1983, Stearns \& Crandall 1984, Stearns \& 
Koella 1986, Rijnsdorp 1993a, Heino et al. 2002b). Of course this does not imply perfect disentanglement, and it has never been claimed that all plastic effects are thus accounted for. What PMRN based on age and length can reliably remove from the description of maturation schedules are the plastic effects of varying average juvenile somatic growth rates. In many wild populations, including those of marine fishes, these effects are likely to be the dominant source of phenotypic plasticity in observed combinations of age and size at maturation.

The possibility of unaccounted for plastic effects has been explicitly acknowledged in several publications employing the PMRN method (e.g. Heino et al. 2002b, Olsen et al. 2004). In particular, such effects reveal themselves as noise in PMRNs. Microenvironmental factors that are unaccounted for lead to probabilistic spread in an estimated PMRN. Macroenvironmental factors that are unaccounted for contribute to this spread, but also to interannual variation in estimated PMRNs. Indeed, time series of PMRNs estimated for adjacent cohorts tend to be noisy. This variability arises from 2 independent sources: observation error and plastic effects not captured by the explanatory variables considered. As observation errors reflect both imperfect sampling and the fact that PMRNs usually cannot be estimated without making simplifying assumptions, it is difficult to tease apart how much of the noise in PMRN estimates can be attributed to either of these 2 sources. However, there can be no doubt that residual plastic effects remain. If potential explanatory variables other than age and length have been measured, one can include these in the PMRN estimation, thereby in theory accounting for more plastic effects. In practice, however, the incorporation of additional explanatory variables, such as weight or condition, is not necessarily warranted, since it may add much more observation error and reliance on simplifying assumptions (Grift et al. 2007).

Some further words of caution may be in order here. In particular, it is tempting to try to learn more about extra plastic effects on maturation by testing for correlations between PMRNs and additional explanatory variables. This approach was applied, for example, by Kraak (2007, this Theme Section) to test for a direct effect of temperature on maturation in North Sea plaice Pleuronectes platessa. As in any other application of time-series analysis, this approach will be acceptable only if there is enough variation in both time series and if long-term trends are absent. The trouble is that fisheries science has been struggling for decades with interpreting long-term maturation trends. Demonstrating that such trends correlate with trends in a potential environmental factor is statistically vacuous: trended time series are always corre- lated. The simple exercise of plotting PMRN midpoints against year - typically showing a declining trendreminds us that fallacious inferences about causation may easily be drawn based on correlation alone. We thus suggest that incorporating environmental factors into the estimation of PMRNs, in addition to cohort or year class, is the only statistically sound approach to the identification and disentanglement of additional plastic effects on maturation.

Even though parallel trends in PMRNs and environmental factors will never be sufficient to establish a causal relationship, they are always necessary for such a relationship to hold. In other words, environmental factors not exhibiting trends matching those observed in a stock's PMRN are unsuitable for explaining such trends. This may seem obvious. However, a study of maturation trends in chum salmon Oncorhynchus keta by Morita \& Fukuwaka (2006, p. 1516) that used 3 growth increments for describing juvenile growth history (as opposed to characterizing it by a single average juvenile growth rate) concluded as follows:

The most recent growth condition was the most important factor affecting whether a fish matured during the subsequent breeding season. Because individuals of similar body size and same age can have different growth histories, the relationship between body size and maturation probability could be plastically modified by growth history. This may violate an assumption required to infer evolution, namely that size-related maturation trends in probabilistic reaction norms are immune to growth history.

These authors are entirely correct in emphasizing that long-term trends in juvenile growth trajectories not yet captured by average juvenile growth rate may confound age- and size-based PMRN estimates. The same confounding effects could very well arise from longterm trends in all the many other factors that, to a greater or lesser extent, are known to affect maturation. What Morita \& Fukuwaka (2006) have not demonstrated, however, is the actual existence of long-term trends in juvenile growth trajectories that go beyond changes in average juvenile growth rate. If such a demonstration were possible, the salient extra explanatory variable(s) should, and could, be included in the PMRN estimation. If not, conclusions based on long-term PMRN trends simply remain unaffected.

\section{Can PMRN analyses conclusively prove fisheries- induced evolution?}

The answer to this question must of course be negative. The reason is that this response should be given to all questions of the type: Can observational phenotypic data conclusively prove evolution to be driven by a specific factor? Conclusively proving fisheries-induced 
evolution would require 2 logically independent conclusions to jointly hold. One needs to address whether the observed change (1) is evolutionary and thus genetic, and (2) has been caused by fishing rather than by another selective force.

In principle, genetic change can be identified either through direct observation or indirectly through the observation of phenotypic change while ruling out relevant environmental change. The first option must be based on collecting and analyzing molecular genetic data. This would require identifying loci strongly affecting maturation, and showing that allele frequencies at these loci have changed in accordance with expectations based on past selection pressures. In addition to the technical question of how the necessary historical tissue samples may be obtained, the major challenge here is to identify the relevant loci and alleles. Genes specifically affecting life-history traits such as maturation in fish remain largely unknown, so proving genetic change in maturation in this manner is not feasible at present. Nevertheless, molecular ecology is developing rapidly, and we may not need to wait for too long before this approach becomes practical.

The second, indirect, option for identifying genetic change is based on common-garden experiments. If individuals of known common ancestry show phenotypic differences despite having been raised under identical conditions for more than 1 generation (to exclude parental effects), then these differences will have to be acknowledged as being of genetic origin. Moreover, if the observed phenotypic differences are larger than those expected from genetic drift alone, they may be interpreted as the result of adaptive evolution undergone since the common ancestry. This approach suffers from 3 drawbacks, and thus also largely remains impractical for demonstrating the genetic nature of temporal maturation trends in marine fish populations. (1) It requires certainty that the populations under investigation are of recent common ancestry. Without some lucky coincidence, this is usually not possible. (2) For common-garden experiments to be capable of controlling for all environmental variation they will often have to depart from strictly natural conditions, so that any observed phenotypic differences will not correspond closely to what is, or has been, going on in the wild. (3) Most importantly, the common-garden approach requires living specimens of the putatively genetically-differentiated populations. This means that when temporal trends are to be investigated, specimens from the ancestral population must not only be alive at present, but must also be 'unevolved' in the sense of not having been exposed to any salient selection pressures in the meantime (e.g. through being kept in captivity). Because of these chal- lenges, common-garden experiments are much more likely to be practical for populations separated in space rather than in time. For example, Koskinen et al. (2002) were able to show rapid evolution in populations of grayling Thymallus thymallus by comparing lifehistory traits in separate contemporary populations stocked from the same source population about a century ago (see Stockwell et al. 2003 for more examples of evolution following introductions).

When it comes to establishing fishing as the cause of a particular life-history change, it has to be recognized that the inadvertent, natural experiments of exposing a specific stock to fishing offer the weakest possible setting - unreplicated and uncontrolled - for demonstrating a causal relationship. However, the credibility of fisheries-induced selection as the most likely causal factor of observed maturation trends may be strengthened in a number of ways.

(1) Alternative hypotheses can be evaluated independently, using the best available knowledge of factors affecting maturation and of changes in the environment. Observations of countertrend variation, as defined in the preceding section, are particularly valuable for this purpose. For example, the tendency of northern cod Gadus morhua to mature at younger ages increased during a period of high fishing intensity and adverse growth conditions (Olsen et al. 2004). This change in maturation is in accordance with expectations based on mortality-induced life-history evolution - toward early maturation when juvenile and adult mortality is high (e.g. Roff 1984, Law \& Grey 1989, Heino 1998) - whereas the plastic effects of slow growth would have been expected to result in just the opposite change. Thus, among these 2 hypotheses, the first is clearly more credible. Naturally, an unlimited number of alternative hypotheses always exists, although all but a few of these will be implausible a priori.

(2) While replication in the strict sense is not feasible, fish stocks are often exposed to a similar 'treatment' in terms of increased fishing mortality. A large number of studies from different geographical areas are showing comparable trends in PMRNs (Heino et al. 2002c, Grift et al. 2003, 2007, Barot et al. 2004b, 2005, Olsen et al. 2004, 2005, Engelhard \& Heino 2004a,b, Dunlop et al. 2005, 2007b, Baulier et al. 2006, Mollet et al. 2006, Haugen \& Vøllestad 2007). The few outliers in this common pattern can be explained by populationspecific characteristics of fisheries regimes or reproductive systems (Engelhard \& Heino 2004a, Dunlop et al. 2007b). Such a ubiquitous pattern is suggestive of a common explanation, for which fisheries-induced evolution is a strong contender.

(3) Numerical models can be constructed that incorporate fishing pressures and other selective forces to systematically investigate the extent to which life- 
history trends observed in nature are captured in these models. So called eco-genetic models account for salient genetic and ecological detail (Dunlop et al. $2007 a, b)$ and are thus emerging as particularly suitable tools for carrying out such exercises (a related approach was used by Baskett et al. 2005). For example, an ecogenetic model of Northeast Arctic cod Gadus morhua shows that the model-predicted rate of PMRN evolution is compatible with observations (Godø et al. 2007). Such findings significantly increase the credibility of fishing as the driver of observed maturation trends, and of lifehistory evolution as the underlying mechanism.

\section{PERSPECTIVES}

To date, the estimation of probabilistic maturation reaction norms (PMRNs) has focused on observational field data from exploited fish stocks. To further our understanding of maturation processes in general, and of the properties of PMRNs in particular, we suggest 2 lines of future experimental research.

(1) Experiments should be implemented to estimate PMRNs under controlled environmental conditions and without the need for invoking simplifying assumptions in the estimation method. Specifically, the phenotypically plastic effects of different environmental factors -including ambient temperature, as well as different temporal sequences of good and bad growth conditions-can thus be systematically explored. These experiments will improve understanding of how low-dimensional PMRNs are affected by unaccounted for sources of phenotypic plasticity.

(2) Breeding experiments should be carried out to make progress with the quantitative genetics of PMRNs. These experiments will provide information on the heritability of PMRNs, as well as about the genetic covariances within PMRNs, and between PMRNs and other heritable life-history traits.

The improved understanding resulting from these 2 lines of experimental research will greatly aid the interpretation of field data and further the accurate modeling of fisheries-induced evolution.

The most exciting application of PMRNs is their contribution to the disentanglement of fisheries-induced evolution and phenotypic plasticity in maturation schedules. Until recently, it has been considered parsimonious to explain these trends as merely plastic effects, usually in response to conditions for accelerated growth resulting from diminished stock size. Ageand size-based PMRNs estimated for more than a dozen fish stocks have captured this main effect of growth-related phenotypic plasticity and have shown that this effect alone cannot explain the observed maturation trends. To overcome this explanation gap, it still has to be evaluated whether there might be other common trends in the environment of fish stocks showing long-term maturation trends that could reasonably be expected to cause plastic responses in maturation schedules. Until such environmental trends are recognized, the most parsimonious explanation of widely observed continual trends in the PMRNs of exploited stocks is fisheries-induced evolution. This is not a proof of fisheries-induced evolution, but a shift in the burden of proof in line with the precautionary approach.

Young et al. (2006) have highlighted the benefits for fisheries management from understanding causal connections between fish physiology and fish life history. Understanding the underpinning of phenotypic plasticity in maturation schedules through the estimation of PMRNs squarely falls into this remit. More generally, fisheries management in the era of the ecosystem approach will increasingly have to rely on stock assessment tools and modeling frameworks that do justice to the age and size structure of fish populations. PMRNs can be seen as useful, if not indispensable, tools for such modern approaches to stock assessment and modeling.

It should be appreciated that, just like maturation, other life-history transitions - including metamorphosis, smolting, and sex change-are also characterized by, often irreversible, adjustments of an individual's morphology or physiology. The same applies to developmental transitions like vitellogenesis, as well as to ontogenetic transitions in meristic or morphometric characters (e.g. Neuman \& Able 2002). While these other life-history transitions may not be as widely taxonomically relevant as maturation, the probabilistic reaction norm approach as discussed in this review will be just as useful in describing and understanding these transitions (e.g. Wilbur \& Collins 1973) as it is in the case of maturation.

The study of evolutionary consequences of fishing can look back on a history of more than 1 century (Rutter 1903, p. 134). However, much of the pioneering empirical work on maturation trends in exploited fish stocks remained inconclusive, so that simple theoretical models and experiments on short-lived species dominated the development of the field. Since evidence from the wild was largely lacking, research on fisheries-induced evolution defined the agenda of a few evolutionary ecologists, but made little impact on the larger community of fisheries scientists and managers. There is no doubt that one of the main reasons for this stagnation was the difficulty of disentangling environmental and genetic influences in phenotypic traits, including maturation. By facilitating the detection of fisheries-induced evolution in maturation schedules, the advent of PMRNs has provided the 
momentum needed for bringing this important topic to the attention of a wider audience. A new generation of fisheries scientists and managers will need tools such as PMRNs for coping with the threats of further undesired fisheries-induced evolution.

Acknowledgements. We gratefully acknowledge financial support from the European Marie Curie Research Training Network FishACE (Fisheries-induced Adaptive Changes in Exploited Stocks), funded through the European Community's Sixth Framework Programme (Contract MRTN-CT2004-005578). M.H. also acknowledges support from the Norwegian Research Council (Project 173417/S40).

\section{LITERATURE CITED}

Alm G (1959) Connection between maturity, size, and age in fishes. Rep Inst Freshw Res, Drottningholm 40:5-145

Barot S, Heino M, O'Brien L, Dieckmann U (2004a) Estimating reaction norms for age and size at maturation when age at first reproduction is unknown. Evol Ecol Res 6: 659-678

Barot S, Heino M, O'Brien L, Dieckmann U (2004b) Longterm trend in the maturation reaction norm of two cod stocks. Ecol Appl 14:1257-1271

Barot S, Heino M, Morgan MJ, Dieckmann U (2005) Maturation of the Newfoundland American plaice (Hippoglossoides platessoides): long-term trends in maturation reaction norms despite low fishing mortality? ICES J Mar Sci 62:56-64

Baskett ML, Levin SA, Gaines SD, Dushoff J (2005) Marine reserve design and the evolution of size at maturation in harvested fish. Ecol Appl 15:882-901

Baulier L, Heino M, Lilly GR, Dieckmann U (2006) Body condition and evolution of maturation of Atlantic cod in Newfoundland. ICES CM 2006/H:19

Beacham TD (1983a) Variability in size and age at sexual maturity of argentine, Argentina silus, on the Scotian Shelf in the Northwest Atlantic Ocean. Environ Biol Fishes 8:67-72

Beacham TD (1983b) Growth and maturity of Atlantic cod (Gadus morhua) in the southern Gulf of St. Lawrence. Can Tech Rep Fish Aquat Sci 1142

Beacham TD (1983c) Variability in median size and age at sexual maturity of Atlantic cod, Gadus morhua, on the Scotian Shelf in the Northwest Atlantic Ocean. US Fish Bull 81:303-321

Beacham TD (1983d) Variability in size and age at sexual maturity of haddock (Melanogrammus aeglefinus) on the Scotian Shelf in the Northwest Atlantic. Can Tech Rep Fish Aquat Sci 1168

Beacham TD (1983e) Variability in size and age at sexual maturity of American plaice and yellowtail flounder in the Canadian Maritimes Region of the Northwest Atlantic Ocean. Can Tech Rep Fish Aquat Sci 1196

Beacham TD (1983f) Variability in size and age at sexual maturity of witch flounder, Glyptocephalus cynoglossus, in the Canadian Maritimes Region of the Northwest Atlantic Ocean. Can Field Nat 97:409-422

Beacham TD (1987) Variation in length and age at sexual maturity of Atlantic groundfish: a reply. Environ Biol Fish 19:149-153

Bernardo J (1993) Determinants of maturation in animals. Trends Ecol Evol 8:166-173
Berrigan D, Koella JC (1994) The evolution of reaction norms: simple models for age and size at maturity. J Evol Biol 7:549-566

Birkeland C, Dayton PK (2005) The importance in fishery management of leaving the big ones. Trends Ecol Evol 20:356-358

Borisov VM (1978) The selective effect of fishing on the population structure of species with a long life cycle. J Ichthyol 18:896-904

Bradshaw AD (1965) The evolutionary significance of phenotypic plasticity in plants. Adv Genet 13:115-155

Burd M, Read J, Sanson GD, Jaffré T (2006) Age-size plasticity for reproduction in monocarpic plants. Ecology 87 : 2755-2764

Conover DO, Munch SB (2002) Sustaining fisheries yields over evolutionary time scales. Science 297:94-96

Conover DO, Schultz ET (1995) Phenotypic similarity and the evolutionary significance of countergradient variation. Trends Ecol Evol 10:248-252

Day T, Rowe L (2002) Developmental thresholds and the evolution of reaction norms for age and size at life history transitions. Am Nat 159:338-350

Dunlop ES, Shuter BJ, Ridgway MS (2005) Isolating the influence of growth rate on maturation patterns in the smallmouth bass (Micropterus dolomieu). Can J Fish Aquat Sci 62:844-853

Dunlop ES, Shuter BJ, Dieckmann U (2007a) The demographic and evolutionary consequences of selective mortality: predictions from an eco-genetic model of the smallmouth bass. Trans Am Fish Soc (in press)

Dunlop ES, Heino M, Dieckmann U (2007b) Eco-genetic models of fisheries-induced adaptive change. In: Dieckmann U, Godø OR, Heino M, Mork J (eds) Fisheries-induced adaptive change. Cambridge University Press, Cambridge (in press)

Edley MT, Law R (1988) Evolution of life histories and yields in experimental populations of Daphnia magna. Biol J Linn Soc 34:309-326

Engelhard GH, Heino M (2004a) Maturity changes in Norwegian spring-spawning herring Clupea harengus: compensatory or evolutionary responses? Mar Ecol Prog Ser 272:245-256

Engelhard GH, Heino M (2004b) Maturity changes in Norwegian spring-spawning herring before, during, and after a major population collapse. Fish Res 66:299-310

Ernande B, Dieckmann U, Heino M (2004) Adaptive changes in harvested populations: plasticity and evolution of age and size at maturation. Proc R Soc Lond Ser B 271:415-423

Fuller T (2003) The integrative biology of phenotypic plasticity. Biol Philos 18:381-389

Gårdmark A, Dieckmann U (2006) Disparate maturation adaptations to size-dependent mortality. Proc R Soc Lond Ser B 273:2185-2192

Garrod, DJ (1967) Population dynamics of the Arcto-Norwegian cod. J Fish Res Board Can 24:145-190

Gavrilets S, Hastings A (1994) A quantitative genetic model for selection on developmental noise. Evolution 48:1478-1486

Gavrilets S, Scheiner S (1993) The genetics of phenotypic plasticity. V. Evolution of reaction norm shape. J Evol Biol 6:31-48

Godø OR (2000) Maturation dynamics of Arcto-Norwegian cod. International Institute for Applied Systems Analysis (IIASA), Laxenburg, Austria: Interim Report IR-00-024. Available at: www.iiasa.ac.at/Admin/PUB/Documents/ IR-00-024.pdf 
Godø OR, Yaragina N, Heino M, Dieckmann U (2007) Effects of fishing on long-term changes in population characteristics of Northeast Arctic cod (Gadus morhua L.). In: Dieckmann U, Godø OR, Heino M, Mork J (eds) Fisheriesinduced adaptive change. Cambridge University Press, Cambridge (in press)

Gomulkiewicz R, Kirkpatrick M (1992) Quantitative genetics and the evolution of reaction norms. Evolution 46:390-411

Goto A (1993) Clinal life-history variation in the river-sculpin, Cottus hangiongensis: an example of phenotypic plasticity. Jpn J Ichthyol 39:363-370

Grift RE, Rijnsdorp AD, Barot S, Heino M, Dieckmann U (2003) Fisheries-induced trends in reaction norms for maturation in North Sea plaice. Mar Ecol Prog Ser 257:247-257

Grift RE, Heino M, Rijnsdorp AD, Kraak SBM, Dieckmann U (2007) Three-dimensional maturation reaction norms for North Sea plaice. Mar Ecol Prog Ser 334:213-224

Handford P, Bell G, Reimchen T (1977) A gillnet fishery considered as an experiment in artificial selection. J Fish Res Board Can 34:954-961

Hansen PM (1949) Studies on the biology of the cod in Greenland waters. Rapp PV Reun Cons Int Explor Mer 123

Hartl DL, Clark AG (1997) Principles of population genetics, 3rd edn. Sinauer Associates, Sunderland, MA

Haugen TO (2000) Growth and survival effects on maturation pattern in populations of grayling with recent common ancestors. Oikos 90:107-118

Haugen TO, Vøllestad L (2007) Case study on grayling. In: Dieckmann U, Godø OR, Heino M, Mork J (eds) Fisheries-induced adaptive change. Cambridge University Press, Cambridge (in press)

Heino M (1998) Management of evolving fish stocks. Can J Fish Aquat Sci 55:1971-1982

Heino M, Dieckmann U, Godø OR (2002a) Measuring probabilistic reaction norms for age and size and maturation. Evolution 56:669-678

Heino M, Dieckmann U, Godø OR (2002b) Estimating reaction norms for age and size at maturation with reconstructed immature size distributions: a new technique illustrated by application to Northeast Arctic cod. ICES J Mar Sci 59:562-575

Heino M, Dieckmann U, Godø OR (2002c) Reaction norm analysis of fisheries-induced adaptive change and the case of the Northeast Arctic cod. ICES CM 2002/Y:14

Heino M, Dieckmann U, Ernande B (2007) Reaction norm analysis of fisheries-induced adaptive change. In: Dieckmann U, Godø OR, Heino M, Mork J (eds) Fisheriesinduced adaptive change. Cambridge University Press, Cambridge (in press)

Huber M, Bengtson DA (1999) Effects of photoperiod and temperature on the regulation of the onset of maturation in the estuarine fish Menidia beryllina (Cope) (Atherinidae). J Exp Mar Biol Ecol 240:285-302

Hutchings JA (1993) Adaptive life histories effected by agespecific survival and growth rate. Ecology 74:673-684

Hylen A, Dragesund O (1973) Recruitment of young ArctoNorwegian cod and haddock in relation to parent stock size. Rapp PV Reun Cons Int Explor Mer 164:57-68

Hylen A, Rorvik CJ (1983) Estimating the maturity ogive for Northeast Arctic cod by a modified mesh assessment model. In: Godø OR, Tilseth S (eds) Reproduction and recruitment of Arctic cod. Proc Soviet-Norwegian Symp, 26-30 Sep 1983, Institute of Marine Research, Bergen, p 153-186

Johnson JB, Belk MC (1999) Effects of predation on lifehistory evolution in Utah chub (Gila atraria). Copeia 1999:948-957
Jørgensen T (1990) Long-term changes in age at sexual maturity of Northeast Arctic cod (Gadus morhua L.). J Cons Int Explor Mer 46:235-248

Koskinen MT, Haugen TO, Primmer CR (2002) Contemporary fisherian life-history evolution in small salmonid populations. Nature 419:826-830

Kraak SBM (2007) Does the probabilistic maturation reaction norm approach disentangle phenotypic plasticity from genetic change? Mar Ecol Prog Ser 335:295-300

Law R (1979) Optimal life histories under age-specific predation. Am Nat 114:399-417

Law R (1991) Fishing in evolutionary waters. New Sci 1758: 35-37

Law R, Grey DR (1989) Evolution of yields from populations with age-specific cropping. Evol Ecol 3:343-359

Marteinsdottir G, Begg GA (2002) Essential relationships incorporating the influence of age, size and condition on variables required for estimation of reproductive potential in Atlantic cod Gadus morhua. Mar Ecol Prog Ser 235:235-256

Maynard Smith J, Haigh J (1974) The hitch-hiking effect of a favourable gene. Genet Res 23:23-35

Metcalfe NA (1998) The interaction between behavior and physiology in determining life history patterns in Atlantic salmon (Salmo salar). Can J Fish Aquat Sci 55:93-103

Miller RB (1957) Have the genetic patterns of fishes been altered by introductions or by selective fishing? J Fish Res Board Can 14:797-806

Mollet FM, Kraak SBM, Rijnsdorp AD (2006) Fisheriesinduced evolutionary changes in maturation reaction norms in North Sea sole (Solea solea). ICES CM 2006/H:14

Morita K, Fukuwaka MA (2006) Does size matter most? The effect of growth history on probabilistic reaction norm for salmon maturation. Evolution 60:1516-1521

Morita K, Morita SH (2002) Rule of age and size at maturity: individual variation in the maturation history of resident white-spotted charr. J Fish Biol 61:1230-1238

Nelson K, Soulé M (1987) Genetical conservation of exploited fishes. In: Ryman N, Utter F (eds) Population genetics and fishery management. Washington Sea Grant Program, Seattle, WA, p 345-368

Neuman MJ, Able KW (2002) Quantification of ontogenetic transitions during the early life of a flatfish, windowpane (Scophthalmus aquosus) (Pleuronectiformes Scophthalmidae). Copeia 2002:597-609

Olsen EM, Heino M, Lilly GR, Morgan MJ, Brattey J, Ernande B, Dieckmann U (2004) Maturation trends indicative of rapid evolution preceded the collapse of northern cod. Nature 428:932-935

Olsen EM, Lilly GR, Heino M, Morgan MJ, Brattey J, Dieckmann U (2005) Assessing changes in age and size at maturation in collapsing populations of Atlantic cod (Gadus morhua). Can J Fish Aquat Sci 62:811-823

Oosthuizen E, Daan N (1974) Egg fecundity and maturity of North Sea cod, Gadus morhua. Neth J Sea Res 8:378-397

Perrin N, Rubin JF (1990) On dome-shaped norms of reaction for size-to-age at maturity in fishes. Funct Ecol 4:53-57

Pigliucci M (2001) Phenotypic plasticity: beyond nature and nurture. Johns Hopkins University Press, Baltimore, MD

Pitt TK (1975) Changes in abundance and certain biological characteristics of Grand Bank American plaice, Hippoglossoides platessoides. J Fish Res Board Can 32: 1383-1398

Policansky D (1983) Size, age, and demography of metamorphosis and sexual maturation in fishes. Am Zool 23:57-63

Polovina JJ (1989) Density dependence in spiny lobster, Panulirus marginatus, in the northwestern Hawaiian Islands. Can J Aquat Fish Sci 46:660-665 
Ponomarenko VP, Ponomarenko IYa, Yaragina NA (1980) Growth and maturation of the Lofoten-Barents Sea cod. ICES CM 1980/G:25

Powles PM (1958) Studies on the reproduction and feeding of Atlantic cod (Gadus callarias L.) in the southwestern Gulf of St. Lawrence. J Fish Res Board Can 15:1383-1402

Reznick DN (1982) The impact of predation on life history evolution in Trinidadian guppies: the genetic components of observed life history differences. Evolution 36: 1236-1250

Reznick DN (1990) Plasticity in age and size at maturity in male guppies (Poecilia reticulata): an experimental evaluation of alternative models of development. J Evol Biol 3: 185-203

Reznick DN (1993) Norms of reaction in fishes. In: Stokes TK, McGlade JM, Law R (eds) The exploitation of evolving resources. Springer-Verlag, Berlin, p 72-90

Reznick DN, Endler JA (1982) The impact of predation on life history evolution in Trinidadian guppies (Poecilia reticulata). Evolution 36:160-177

Reznick DN, Ghalambor CK (2005) Can commercial fishing cause evolution? Answers from guppies (Poecilia reticulata). Can J Fish Aquat Sci 62:791-801

Reznick DN, Bryga H, Endler JA (1990) Experimentally induced life-history evolution in a natural population. Nature 346:357-359

Reznick DN, Butler MJ, Rodd FH, Ross P (1996) Life history evolution in guppies (Poecilia reticulata). 6. Differential mortality as a mechanism for natural selection. Evolution 50:1651-1660

Reznick DN, Shaw FH, Rodd FH, Shaw RG (1997) Evaluation of the rate of evolution in natural populations of guppies (Poecilia reticulata). Science 275:1934-1937

Ricker WE (1981) Changes in the average size and average age of Pacific salmon. Can J Fish Aquat Sci 38:1636-1656

Rijnsdorp AD (1989) Maturation of male and female North Sea plaice (Pleuronectes platessa L.). J Cons Int Explor Mer 46:35-51

Rijnsdorp AD (1993a) Fisheries as a large-scale experiment on life-history evolution: disentangling phenotypic and genetic effects in changes in maturation and reproduction of North Sea plaice, Pleuronectes platessa L. Oecologia 96:391-401

Rijnsdorp AD (1993b) Selection differentials in male and female North Sea plaice and changes in maturation and fecundity. In: Stokes TK, McGlade JM, Law R (eds) The exploitation of evolving resources. Springer-Verlag, Berlin, p 19-36

Roff DA (1984) The evolution of life history parameters in teleosts. Can J Fish Aquat Sci 41:989-1000

Roff DA (1991) The evolution of life-history variation in fishes, with particular reference to flatfishes. Neth J Sea Res 27: 197-207

Rollefsen G (1938) Changes in the mean age and growth-rate of the year-classes in the Arcto-Norwegian stock of cod. Rapp PV Reun Cons Int Explor Mer 158:58-64

Rollefsen G (1953) Observations on the cod and cod fisheries of Lofoten. Rapp PV Reun Cons Int Explor Mer 136:40-47

Rutter C (1903) Natural history of the quinnat salmon. A report on investigations in the Sacramento River, 1886-1901. Bull US Fish Comm 22:65-141

Sarkar S (1999) From the Reaktionsnorm to the adaptive norm: the norm of reaction, 1909-1960. Biol Philos 14: 235-252

Sarkar S, Fuller T (2003) Generalized reaction norms for

Editorial responsibility: Howard Browman (Associate Editorin-Chief), Storebø, Norway ecological developmental biology. Evol Dev 5:106-115 Schaffer WM, Elson PF (1975) The adaptive significance of variations in life history among local populations of Atlantic salmon in North America. Ecology 56:577-590

Schlichting CD (1986) The evolution of phenotypic plasticity in plants. Annu Rev Ecol Syst 17:667-693

Schlichting CD, Pigliucci M (1998) Phenotypic evolution: a reaction norm perspective. Sinauer Associates, Sunderland, MA

Schmalhausen II (1949) Factors of evolution: the theory of stabilizing selection. Blakiston, Philadelphia, PA

Sheridan AK (1995) The genetic impacts of human activities on wild fish populations. Rev Fish Sci 3:91-108

Smith PJ (1994) Genetic diversity of marine fisheries resources: possible impacts of fishing. FAO Fish Tech Pap No 344

Stearns SC (1983) The evolution of life-history traits in mosquitofish since their introduction to Hawaii in 1905: rates of evolution, heritabilities, and developmental plasticity. Am Zool 23:65-75

Stearns SC (1992) The evolution of life histories. Oxford University Press, Oxford

Stearns SC, Crandall RE (1984) Plasticity for age and size at sexual maturity: a life-history response to unavoidable stress. In: Potts G, Wootton RJ (eds) Fish reproduction. Academic Press, London, p 13-33

Stearns SC, Koella JC (1986) The evolution of phenotypic plasticity in life-history traits: predictions of reaction norms for age and size at maturity. Evolution 40:893-913

Stockwell CA, Hendry AP, Kinnison MT (2003) Contemporary evolution meets conservation biology. Trends Ecol Evol 18:94-101

Stokes TK, McGlade JM, Law R (1993) The exploitation of evolving resources. Lecture notes in biomathematics, Vol 99. Springer-Verlag, Berlin

Sutherland WJ (1990) Evolution and fisheries. Nature 344: $814-815$

Templeman W, Bishop CA (1979) Sexual maturity and spawning in haddock, Melanogrammus aeglefinus, of St. Pierre Bank. Int Comm Northwest Atl Fish Res Bull 14:77-83

Templeman W, Hodder VM, Wells R (1978) Sexual maturity and spawning in haddock, Melanogrammus aeglefinus, of the southern Grand Bank. Int Comm Northwest Atl Fish Res Bull 13:53-65

Thorpe JE, Mangel M, Metcalfe NB, Huntingford FA (1998) Modelling the proximate basis of salmonid life-history variation, with application to Atlantic salmon. Evol Ecol 12:581-599

Tikhonov VI (1977) Changes in fecundity and maturation of the yellowfin sole. Biol Moriya 3:64-69

Trippel EA (1995) Age at maturity as a stress indicator in fisheries. BioScience 45:759-771

Van Dooren TJM, Tully T, Ferrière R (2005) The analysis of reaction norms for age and size at maturity using maturation rate models. Evolution 59:500-506

Wilbur HM, Collins JP (1973) Ecological aspects of amphibian metamorphosis. Science 182:1305-1314

Woltereck R (1909) Weitere experimentelle Untersuchungen über Artveränderung, speziell über das Wesen quantitativer Artunterschiede bei Daphnien. Verh Dtsch Zool Ges 19:110-173

Young JL, Bornik ZB, Marcotte ML, Charlie KN, Wagner GN, Hinch SG, Cooke SJ (2006) Integrating physiology and life history to improve fisheries management and conservation. Fish Fish 7:262-283

Submitted: December 12, 2006; Accepted: February 13, 2007 Proofs received from author(s): March 24, 2007 